\title{
Family-Based Intervention Program for Parents of Substance-Abusing Youth and Adolescents
}

\author{
David Bisetto Pons, ${ }^{1,2}$ Remedios González Barrón, ${ }^{1}$ and Álvaro Botella Guijarro \\ ${ }^{1}$ Faculty of Psychology, University of Valencia, Valencia, Spain \\ ${ }^{2}$ AEPA Foundation, Alicante, Spain \\ Correspondence should be addressed to Álvaro Botella Guijarro; alvarbot@fundacion-aepa.org
}

Received 27 April 2016; Revised 14 August 2016; Accepted 14 September 2016

Academic Editor: Richard Midford

Copyright (C) 2016 David Bisetto Pons et al. This is an open access article distributed under the Creative Commons Attribution License, which permits unrestricted use, distribution, and reproduction in any medium, provided the original work is properly cited.

\begin{abstract}
The use of drugs among adolescents/youth often results in a high degree of distress for the family members who live with them. This in turn can lead to a deterioration of mental (psychological) health, hindering any attempt to successfully cope with the situation. The goal of our research was to study the effect of the Community Reinforcement and Family Training (CRAFT) program on parents of adolescents/young adult drug users. Study volunteers $(n=50)$ were parents from Valencia (Spain) that were divided into two groups. The experimental group $(n=25)$ was made up of parents whose sons and daughters exhibited problems with drug use and the constructed noncausal baseline group $(n=25)$ was made up of parents whose sons and daughters did not show any substance abuse problems. For both groups, self-esteem (Rosenberg Self-Esteem Scale), depression (BDI-II), anxiety (STAI), and anger (STAXI-II) were evaluated before and after the application of the CRAFT program. Results show a significant improvement in the experimental group's self-esteem, depression, and anger state and a decrease in negative moods. These changes in parents produce a positive effect on their substance-using sons and daughters: of the 25 participants, 15 contacted specialized addiction treatment resources for the first time.
\end{abstract}

\section{Introduction}

There are a considerable number of studies which suggest that parents and other relatives of adolescent/young adult substance users experience a high degree of distress and family conflict that could result in a deterioration of mental health $[1,2]$. The negative impact on the family of adolescents/youth with substance use problems is comparable to the impact on people living with an adult with the same problem [2]. It is estimated that approximately five people close to the adult substance abuser will be directly affected by their addiction. This figure also holds true for families of adolescent/young adult substance user [3]. The adverse effects experienced by the parents of substance users take the form of physical, mental, and social stress which can lead to depression, somatic ailments, low self-esteem, a high degree of anxiety and anger, fear that their son/daughter is in danger, despair, guilt, and pain arising from the feeling that they have failed as parents $[2,4-6]$. In the words of Orford et al. [4], affected family members are "ordinary people trying to cope with highly stressful experiences." All of these manifestations are similar to those experienced during prolonged periods of stress or adversity, such as war, long-term unemployment, one's own chronic illness, or the illness of a family member living in the same household [5].

Furthermore, the importance of family support during the recovery process of a person with a substance abuse disorder has been widely shown. For instance, Casas and Gossop [7] suggest that family pressure has an influence on the user's decision to stop using alcohol or other drugs (hereinafter AOD). Levy [8], in his five-year follow-up study of narcotic addicts, found that subjects who overcame addiction usually did so because family support was part of the process.

Booth et al. [9] found that family support received by substance users during addiction treatment led to increased self-esteem and personal efficacy and led them to remain in treatment as a result. López-Torrecilla et al. [10] indicate a greater degree of personal efficacy among substance 
users whose relatives were involved in their addiction treatment.

Similarly, for adolescent/young adult substance users, a number of authors have observed that family support favors the processes of detection, prevention of problematic drug use, and probability of initiating and remaining in treatment [11-14]. Improvement has also been observed in individual treatment programs, leading to fewer relapses, improved family relations, and a higher probability of reducing the use of AOD among substance users [15]; these substance users are also more likely to distance themselves from settings and relationships associated with AOD abuse behaviors [16, 17], helping them put an end to drug abuse [18].

The following data is a summary of the situation in Spain regarding the use of AOD among adolescents/youth: adolescents start using drugs between the ages of 13 and 16 for most substances. Alcohol, tobacco, and cannabis continue to be the most frequently used drugs among Spanish adolescents/youth. It was estimated that $52.2 \%$ of youth aged between 15 and 24 years smoke cannabis [19]. In addition, cannabis use is the reason for $93 \%$ of all requests for treatment among adolescents between 14 and 18 years of age; this indicates a growing trend in the problematic or high-risk use of cannabis, which is associated with lower academic performance $[19,20]$.

As a developmental stage, adolescence/youth is marked by significant psychological, physiological, and social changes [21]. For this reason, it is considered a stage where the young adult is most at risk, favoring the appearance of mental disorders such as anxiety, impulsive and aggressive behavior, stress, and depression [22-24], which are associated with a greater degree of family conflict [25]. This is coupled with an observed desire to experiment with substances while playing down the danger they pose, overconfidence, and a false sense of being in control. All of these factors increase the risk of suffering from problems associated with the use/abuse of AOD [26] and increase the chance of developing drug dependency problems in the future [27-29] which may not be seen by the substance abuser as being problematic [30].

In summary, studies indicate the existence of an adolescent/young adult population with substance use problems. This risky use of AOD and the circumstances that often surround this behavior have been shown to affect the mental health of their families, among other reasons, because this situation exposes family members to a high degree of stress. When they appear, these effects on the mental health of other members of the family make it more difficult for the same family members to act appropriately when it comes to detecting and preventing substance use and also prevent them from initiating and remaining in an addiction treatment program. In light of these considerations, effective addiction treatment should include support for family members, empowering them to take control of the situation wherever they can.

There are a number of empirically validated intervention programs which work towards improving mental distress experienced by close relatives of adolescents/youth who are substance abusers [1]; these include the 5-Step Method [31], the Adolescent Transition Program (ATP) [32], BEST, and BEST-Plus [33, 34].
The Community Reinforcement and Family Training (CRAFT) program developed by Smith and Meyers [35] has been found to be effective in both adults resistant to starting treatment [36] and adolescent/young adult substance abusers [37]. This treatment program has been found to improve the mental health of non-substance-abusing family members by encouraging the adolescent to cease using said substances $[38,39]$. The CRAFT program is recommended when working with non-substance-abusing family members because it increases their self-esteem, improves symptoms associated with depression and anxiety, and reduces distress and anger $[36,40]$.

The CRAFT program [35] is divided into two large sections. The first provides training in behavior modification techniques. This section consists of the following components: strategies that encourage participants to actively engage in treatment, identification of high-risk situations through a functional analysis of the family member's drugusing behavior, prevention of domestic violence, training in positive communication skills, identification of activities which reinforce positive behavior and compete with drug use, training on how to remove reinforcement of substanceabusing behavior, assistance to family members in planning lifestyle changes in those areas of their lives which they feel are unsatisfactory, problem solving, and training that helps them encourage adolescents with drug problems to enter addiction treatment program or seek out specialized assistance.

The second portion of the program focuses on the adolescent/young adult once they have entered addiction treatment program with the support of their family.

In this study, the program was adapted for use on a Spanish group of participants. It was implemented using the group therapy approach developed by Foote and Manuel [41].

The objective of this pilot study was to analyse, in the Spanish population, how the first part of the CRAFT program helps parents of adolescent/young adult substance users acquire or use skills that allow them to improve their mental well-being and therefore assist their children in initiating an addiction treatment program [42].

To this end, the following working hypotheses have been established.

(a) There are statistically significant differences in selfesteem, depression, state anxiety and trait anxiety, state anger, trait anger, and anger expression index (AX Index) scores between the group comprising family members of adolescent/young adult substance users before treatment and the group of family members who state that they do not have any problems (the noncausal baseline group).

(b) The family members targeted by the intervention will show improved scores in the variables mentioned above, obtained after treatment, when compared to scores obtained prior to treatment.

(c) Scores obtained after treatment for study variables will not differ significantly from those obtained in the constructed noncausal baseline group. 
(d) At least $50 \%$ of the members of the experimental group will help their substance-abusing relative to seek out help from a specialized resource for the treatment and indicate prevention of substance abuse (Addictive Behavior Unit and Community Prevention Unit) before treatment program completion (ten weeks).

\section{Materials and Methods}

2.1. Research Classification. The study is a quantitative, pretreatment, and posttreatment study with a constructed noncausal baseline (hereafter CNCB) $[43,44]$. The "baseline" here refers to the scores obtained in the study variables by the parents who did not have adolescent/youth with AOD use problems.

2.2. Participants. To carry out the study, the authors performed convenience sampling. The parents of adolescent/ young adult substance users were referred from the Addictive Behavior Unit (Spanish acronym: UCA), Community Prevention Unit (Spanish acronym: UPCCA), and the Social Services Department. These resources were contacted to offer the intervention program for parents with adolescent/young adult substance users. None of the participants had a family history of addiction.

All participants stated that none of the siblings of substance users had experienced problems associated with drug use.

All of the parents in the first group claim to have or have had mental, social, and even somatic problems and a family atmosphere they classify as being either "quite bad" or "very bad."

At the same time, convenience sampling was performed to select participants for the CNCB group. These were parents whose sons or daughters did not have any substance use problems and were not suffering from any other stressful life situations that could give rise to similar symptoms of distress. This information was provided by the parents themselves.

2.3. Instruments. Sociodemographic characteristics were collected by way of a semistructured interview conducted with each of the participants, adapted from Cortés-Tomás and Pascual-Pastor [45].

Self-esteem was evaluated through Rosenberg's Self-Esteem Scale [46], adapted by Echeburúa [47], and consisting of ten items answered on a four-point scale (1: strongly agree, 2: agree, 3: disagree, and 4: strongly disagree). The reliability and validity of this instrument are 0.87 and 0.72 , respectively [48].

To evaluate depression, the Beck Depression Inventory (BDI-II) was used [49]. This inventory is composed of 21 items, each with four possible responses that are assigned a score indicating the severity of the symptom (arranged in order from mild to severe). It has a high internal consistency, in both clinical and nonclinical samples, with an alpha score of 0.92 . The Spanish version of this test also shows high internal consistency both in samples with university students (0.80) and in general or clinical population [50].
Anxiety was evaluated using the State-Trait Anxiety Inventory (STAI) [51], composed of two Likert-type scales with a total of 40 items that measure state anxiety (A-State) and trait anxiety (A-Trait). As far as reliability and validity are concerned, this inventory has been tested on the Spanish population and shows an internal consistency of between 0.90 and 0.93 for state anxiety and between 0.84 and 0.87 for trait anxiety.

Anger was evaluated through the State-Trait Anger Expression Inventory (STAXI-2) [52]. The items that it contains measure state, trait, and expression of anger [53]. The inventory shows good psychometric properties that are internally consistent with an alpha score of 0.89 for the State Anger Scale and 0.82 for the Trait Anger Scale.

2.4. Procedure. Once the participants of the experimental group were referred by the various collaborating bodies, they were evaluated by a psychologist using the instruments described above.

The experimental group set to receive the adapted CRAFT program was divided into four smaller intervention groups [35], consisting of six participants each, except for one group, which had seven participants. Each intervention consisted of ten weekly sessions lasting one hour and thirty minutes each. The sessions were given by the same therapists.

2.5. Data Analysis. The percentage of families with problems associated with AOD use that sought out some kind of addiction treatment or intervention at some time during the study was calculated based on the information provided by the parents attending the group sessions.

An exploratory analysis was conducted to identify possible outliers and missing data and determine data distribution, symmetry, kurtosis, homoscedasticity, and other aspects. These analyses revealed that, given the study samples, it could not be stated that the data are from a normally distributed population for the variables under study (ShapiroWilk test). Furthermore, outlying scores were found for all variables, and the variances of the groups to be compared were found to be equal (Levene's test to assess homogeneity of variance).

In light of the above findings, the authors decided to use nonparametric tests for inferential analyses. While these tests offer statistical robustness, they have less power; that is, their $p$ values tend to be higher and there is a greater chance of type II errors.

Scores obtained before treatment were compared to scores taken after treatment in the experimental group, using the Wilcoxon signed-rank test, the nonparametric version of the $t$-test for dependent samples.

Scores at pretreatment for each variable were compared to scores from the constructed noncausal baseline group to see if there were differences in the study variables between families of adolescent/young adult substance abusers before intervention and families that stated that they did not have any drug-related problems. To make this comparison, the Mann-Whitney $U$ test was used, which is the nonparametric equivalent to the $t$-test for independent samples. 
TABLE 1: Sociodemographic variables (in \%, except age, in years).

\begin{tabular}{|c|c|c|c|}
\hline & Experimental group & CNCB group & Children of EG members with AOD use problem \\
\hline \multicolumn{4}{|l|}{ Sex } \\
\hline Male & 24 & 32 & 98 \\
\hline Female & 76 & 68 & 2 \\
\hline \multicolumn{4}{|l|}{ Age } \\
\hline Mean & 51.6 & 48.2 & 21.4 \\
\hline Standard deviation & 6.8 & 8.3 & 4.8 \\
\hline \multicolumn{4}{|l|}{ Marital status } \\
\hline Married or domestic partnership & 88 & 84 & \\
\hline Separated or divorced & 12 & 12 & \\
\hline Widow/er & - & 4 & \\
\hline \multicolumn{4}{|l|}{ Number of children } \\
\hline 1 & 8 & 4 & \\
\hline 2 & 92 & 88 & \\
\hline 3 & - & 8 & \\
\hline \multicolumn{4}{|l|}{ Educational level } \\
\hline Primary education & 84 & 64 & 96 \\
\hline Secondary education & 8 & 24 & 4 \\
\hline Higher education & 8 & 12 & - \\
\hline \multicolumn{4}{|l|}{ Principal drug } \\
\hline Cannabis & & & 56 \\
\hline Cocaine & & & 28 \\
\hline Alcohol & & & 12 \\
\hline Heroin & & & 4 \\
\hline
\end{tabular}

Lastly, the scores taken from the experimental group after treatment were compared to those of the noncausal baseline group to determine whether any differences observed before treatment between the substance-user family member group and the CNCB group had diminished. The Mann-Whitney $U$ test was also employed for this analysis.

Effect sizes were calculated for each comparison, using the formula $r=Z / \sqrt{N}$, where $r$ is the effect size, $Z$ is the $U$ or $W$ score, depending on the test employed, converted to a $Z$ score, and $N$ is the total size of the sample, that is, the sum of both sample sizes of each group (50 in this case). The coefficient of determination $\left(r^{2}\right)$ was calculated to allow for a better interpretation of the effect size according to the proportion of explained variance.

To conduct this statistical analysis, the $\mathrm{R}$ computing software environment was used, version 3.2.3 Wooden Christmas-Tree, released 10-12-2015, using the coin package [54], with the RStudio integrated development environment, version 0.99.491.

\section{Results}

A summary of sociodemographic variables is provided in Table 1 . No statistically significant differences were observed between the experimental and constructed noncausal baseline groups in terms of parental age $(t(48)=-1.80 ; p=0.078$, two-tailed $)$ or gender $\left(x^{2}(1, N=50)=0.397 ; p=0.754\right.$, two-tailed).
Hypothesis $a$. The results obtained before treatment by the experimental group, when compared to those obtained from the $\mathrm{CNCB}$ group, show statistically significant differences $(p<0.01)$ for all variables except state anxiety and anger expression index (AX Index) (Table 2).

In particular significant differences were found in selfesteem $(p<0.01)$, where the means were found to be higher for the constructed noncausal baseline group. The experimental group showed higher means for depression $(p<$ $0.01)$, trait anxiety $(p<0.01)$, and state anger and trait anger $(p<0.01)$. The effect sizes $(r)$ indicate a correlation between the particular group each member belongs to and each of the variables, in terms of absolute values. For instance, for the self-esteem variable, a correlation of 0.65 was found between membership to one of the groups and self-esteem scores. The determination coefficient $\left(r^{2}\right)$ indicates the percentage of variance which predicts membership to one or the other group. For the self-esteem variable, this was found to be $42.2 \%$.

Hypothesis $b$. Pretreatment and posttreatment results were compared for the experimental group (Table 3). All of the variables under study improved, with statistically significant differences obtained for self-esteem $(p<0.01)$, depression $(p<0.01)$, and state anger $(p<0.01)$. Participants who completed the program experienced greater self-esteem and showed reduced scores in terms of depression and state anger. The treatment explained $35 \%, 24 \%$, and $15 \%$ of the variance of these scores, respectively. 
TABLE 2: Comparison between experimental group (before treatment) and CNCB group.

\begin{tabular}{|c|c|c|c|c|c|c|c|c|c|c|}
\hline \multirow{2}{*}{ Variables } & \multirow{2}{*}{ Instrument } & & \multicolumn{2}{|c|}{ Experimental group (before treatment) } & \multicolumn{2}{|c|}{ CNCB group } & \multirow{2}{*}{$Z$} & \multirow{2}{*}{$p$} & \multirow{2}{*}{$\mathrm{TE}(r)$} & \multirow{2}{*}{$r^{2}$} \\
\hline & & & Mean & SD & Mean & $\mathrm{SD}$ & & & & \\
\hline \multirow{7}{*}{ Emotional variables } & Rosenberg & Self-esteem & 27.88 & 4.81 & 33.56 & 2.65 & 5.18 & $0.000^{* *}$ & 0.65 & 0.42 \\
\hline & BDI-II & Depression & 13.82 & 10.12 & 2.60 & 2.90 & -5.07 & $0.000^{* *}$ & 0.60 & 0.36 \\
\hline & \multirow{2}{*}{ STAI } & S. anxiety & 27.04 & 11.41 & 24.36 & 6.95 & -1.00 & 0.478 & 0.10 & 0.01 \\
\hline & & T. anxiety & 27.46 & 9.78 & 22.24 & 6.93 & -2.09 & $0.006^{* *}$ & 0.38 & 0.14 \\
\hline & \multirow{3}{*}{ STAXI-2 } & S. anger & 24.36 & 9.97 & 17.72 & 3.34 & -3.16 & $0.001^{* *}$ & 0.44 & 0.19 \\
\hline & & T. anger & 19.68 & 5.07 & 16.04 & 3.36 & -2.99 & $0.009^{* *}$ & 0.37 & 0.14 \\
\hline & & $\mathrm{AEI}^{1}$ & 29.80 & 12.26 & 27.36 & 8.13 & -0.83 & 0.443 & 0.11 & 0.01 \\
\hline
\end{tabular}

${ }^{1}$ Anger expression index.

** $(p<0.01)$.

TABLE 3: Effect of treatment on study variables in experimental group.

\begin{tabular}{|c|c|c|c|c|c|c|c|c|c|c|}
\hline \multirow{3}{*}{ Variables } & \multirow{3}{*}{ Instrument } & & \multicolumn{4}{|c|}{ Experimental group } & \multirow{3}{*}{$Z$} & \multirow{3}{*}{$p$} & \multirow{3}{*}{$\mathrm{TE}(r)$} & \multirow{3}{*}{$r^{2}$} \\
\hline & & & \multicolumn{2}{|c|}{ Pre } & \multicolumn{2}{|c|}{ Post } & & & & \\
\hline & & & Mean & SD & Mean & $\mathrm{SD}$ & & & & \\
\hline \multirow{7}{*}{ Emotional variables } & Rosenberg & Self-esteem & 27.88 & 4.81 & 32.28 & 4.56 & -4.197 & $0.000^{* *}$ & 0.59 & 0.35 \\
\hline & BDI-II & Depression & 13.82 & 10.12 & 8.80 & 8.52 & 3.480 & $0.000^{* *}$ & 0.49 & 0.24 \\
\hline & \multirow{2}{*}{ STAI } & S. anxiety & 27.04 & 11.41 & 24.20 & 10.43 & 1.333 & 0.188 & 0.19 & 0.04 \\
\hline & & T. anxiety & 27.46 & 9.78 & 25.88 & 11.60 & 0.444 & 0.667 & 0.06 & 0.00 \\
\hline & \multirow{3}{*}{ SATXI-2 } & S. anger & 24.36 & 9.97 & 20.20 & 8.67 & 2.764 & $0.004^{* *}$ & 0.39 & 0.15 \\
\hline & & T. anger & 19.68 & 5.07 & 19.04 & 6.34 & 0.203 & 0.847 & 0.03 & 0.00 \\
\hline & & $\mathrm{AEI}^{1}$ & 29.80 & 12.26 & 25.64 & 11.02 & 1.496 & 0.139 & 0.21 & 0.04 \\
\hline
\end{tabular}

${ }^{1}$ Anger expression index.

${ }^{* *}(p<0.01)$.

TABLE 4: Comparison between experimental group (after treatment) and CNCB group.

\begin{tabular}{|c|c|c|c|c|c|c|c|c|c|c|}
\hline \multirow{2}{*}{ Variables } & \multirow{2}{*}{ Instrument } & & \multicolumn{2}{|c|}{ Experimental group (after treatment) } & \multicolumn{2}{|c|}{ CNCB group } & \multirow{2}{*}{$Z$} & \multirow{2}{*}{$p$} & \multirow{2}{*}{$\mathrm{TE}(r)$} & \multirow{2}{*}{$r^{2}$} \\
\hline & & & Mean & SD & Mean & $\mathrm{SD}$ & & & & \\
\hline \multirow{7}{*}{ Emotional variables } & Rosenberg & Self-esteem & 32.28 & 4.56 & 33.56 & 2.65 & 1.31 & 0.195 & 0.18 & 0.03 \\
\hline & BDI-II & Depression & 8.80 & 8.52 & 2.60 & 2.90 & -2.74 & $0.006^{* *}$ & 0.39 & 0.15 \\
\hline & \multirow{2}{*}{ STAI } & S. anxiety & 24.20 & 10.43 & 24.36 & 6.95 & 0.29 & 0.776 & 0.04 & 0.00 \\
\hline & & T. anxiety & 25.88 & 11.60 & 22.24 & 6.93 & -1.43 & 0.156 & 0.20 & 0.04 \\
\hline & \multirow{3}{*}{ STAXI-2 } & S. anger & 20.20 & 8.67 & 17.72 & 3.34 & -0.58 & 0.566 & 0.08 & 0.01 \\
\hline & & T. anger & 19.04 & 6.34 & 16.04 & 3.36 & -1.99 & $0.045^{*}$ & 0.28 & 0.08 \\
\hline & & $\mathrm{AEI}^{1}$ & 25.64 & 11.02 & 27.36 & 8.13 & 0.15 & 0.881 & 0.02 & 0.00 \\
\hline
\end{tabular}

${ }^{1}$ Anger expression index.

$*(p<0.05)$.

${ }^{* *}(p<0.01)$.

Hypothesis c. Posttreatment scores were compared with scores obtained from constructed noncausal baseline group (Table 4). Differences decreased for all variables once the intervention program was completed; however, only the depression and trait anger variables showed statistically significant differences with respect to the constructed noncausal baseline group, with a small effect size (15\%) for depression and very small one ( $8 \%)$ for trait anxiety.

Hypothesis d. The percentage of family members with substance abuse problems who sought out some kind of treatment or intervention service for their problem was found to be $60 \%$ ( 15 out of 25 ), according to the information gathered during the study period, that is, before treatment program completion.

\section{Discussion}

Although improvement was not observed in all the variables under study as was posited in Hypothesis b, the parents of substance-abusing adolescents/youth who took part in the program did show increased self-esteem and improved mood and anger expression, which is in keeping with previous studies $[6,23,24]$. This improvement in mental health gave 
rise to scores similar to those observed in the $\mathrm{CNCB}$ group (Hypothesis c), which is in line with a similar study in the field [39].

The results obtained in this study suggest that the CRAFT program [35], when applied to families of adolescent/young adult substance users, seems to yield results that are in line with those obtained in research conducted on other nonSpanish populations $[6,23,24,37,42]$. Not only does the therapy conducted as part of this program seem to have a beneficial effect on the mental well-being of parents, but it also gives them the tools they need to encourage their children to enter addiction treatment [17] that will help them reduce and/or cease using drugs [15]. In this study, $60 \%$ of the substance-abusing adolescents/young adults contacted a treatment program of one kind or another. These results are in keeping with other research in this field that has yielded results ranging between $55 \%$ and $86 \%[6,11,37,38,40,42]$.

A survey of the literature in this field shows that substance abuse among adolescents/youth has a negative impact on the mental health of parents and other family members who live with substance abusers. This gives rise to symptoms such as physical, mental, and social stress. According to the data obtained from this study, these symptoms lead to low selfesteem, depression, stable anxiety, and anger. This makes it difficult to address substance use and leads to a high degree of powerlessness as they do not know how to proceed in such situations [16].

\section{Conclusions}

From this study it was not possible to ascertain if the CRAFT program works by empowering participants, improving mental health, and providing them with the strength they need to effectively deal with their situation using their own resources, in keeping with Orford et al. [4] and Copello et al. [31], if it works because it gives parents new skills (communication, contingency management, and problem solving) which allow them to take control of the family situation [35], or if it involves a combination of both mechanisms. What the study seems to show is that the CRAFT program generates a change in family atmosphere which encourages the adolescent/young adult to enter treatment, improving the mental health of their family members.

This study showed some limitations, which meant that we cannot deem its results to be conclusive. This is mainly due to the study design type, sample size, and the fact that a followup of the program at 12 months was not possible. The sample size of the CNCB (similar to that of the experimental group but comprising family members that were not experiencing a stressful family situation) was too reduced to serve as a gauge for a population; for its creation, the study team relied solely upon the information provided to them by the parents themselves. With regard to design, CNCB group is a nonequivalent comparison group. Despite these limitations, the results are encouraging, and further research along these lines would allow us to perfect and build upon this approach in the treatment of families of adolescents/youth with substance abuse problems.

\section{Consent}

All of the participants signed an informed consent form in order to participate in the study. They were also informed that their personal information and questionnaire results would remain anonymous and confidential.

\section{Competing Interests}

The authors declare that there are no competing interests.

\section{References}

[1] E. Y. N. Yuen and J. W. Toumbourou, "Does family intervention for adolescent substance use impact parental mental health? A systematic review," Australian e-Journal for the Advancement of Mental Health, vol. 7, no. 3, pp. 186-199, 2008.

[2] P. Hussaarts, H. G. Roozen, R. J. Meyers, B. J. M. van de Wetering, and B. S. McCrady, "Problem areas reported by substance abusing individuals and their concerned significant others," The American Journal on Addictions, vol. 21, no. 1, pp. 38-46, 2012.

[3] D. C. Daley and M. Raskin, Treating the Chemically Dependent and Their Families, Sage, Newbury Park, Calif, USA, 1991.

[4] J. Orford, A. Copello, R. Velleman, and L. Templeton, "Family members affected by a close relative's addiction: the stressstrain-coping-support model," Drugs: Education, Prevention and Policy, vol. 17, no. 1, pp. 36-43, 2010.

[5] J. Orford, R. Velleman, A. Copello, L. Templeton, and A. Ibanga, "The experiences of affected family members: a summary of two decades of qualitative research," Drugs: Education, Prevention and Policy, vol. 17, no. 1, pp. 44-62, 2010.

[6] X. Guo, N. Slesnick, and X. Feng, "Reductions in depressive symptoms among substance-abusing runaway adolescents and their primary caretakers: a randomized clinical trial," Journal of Family Psychology, vol. 28, no. 1, pp. 98-105, 2014.

[7] M. Casas and M. Gossop, Tratamientos Psicológicos en Drogodependencias. Recaída y Prevención de Recaídas, Generalitat de Catalunya, Barcelona, Spain, 1993.

[8] B. S. Levy, "Five years after: a follow-up of 50 narcotic addicts," The American Journal of Psychiatry, vol. 128, no. 7, pp. 868-872, 1972.

[9] B. M. Booth, D. W. Russell, S. Soucek, and P. R. Laughlin, "Social support and outcome of alcoholism treatment: an exploratory analysis," The American Journal of Drug and Alcohol Abuse, vol. 18, no. 1, pp. 87-101, 1992.

[10] F. López-Torrecilla, M. Bulas, R. León-Arroyo, and I. Ramírez, "Influencia del apoyo familiar en la autoeficacia de los drogodependientes," Adicciones: Revista de Socidrogalcohol, vol. 17, no. 3, pp. 241-251, 2005.

[11] L. W. Dutcher, R. Anderson, M. Moore et al., "Community Reinforcement and Family Training (CRAFT): an effectiveness study," Journal of Behavior Analysis in Health, Sports, Fitness and Medicine, vol. 2, no. 1, pp. 80-90, 2009.

[12] J. Bobes, M. Casas, and M. Gutiérrez, "Abordaje de las adicciones en poblaciones especiales. Ancianos y drogodependencias," in Manual de Trastornos Adictivos, C. Romero, D. Bachiller, E. Ros, and M. Casas, Eds., pp. 268-275, Adamed, Madrid, Spain, 2011.

[13] S. A. Baldwin, S. Christian, A. Berkeljon, and W. R. Shadish, "The effects of family therapies for adolescent delinquency and 
substance abuse: a meta-analysis," Journal of Marital and Family Therapy, vol. 38, no. 1, pp. 281-304, 2012.

[14] C. López, C. Bruzzone, M. Krebs, and X. Castro, "La intervención motivacional y sus efectos sobre la entrada a tratamiento de adicción," Revista de Psicología, vol. 22, no. 1, pp. 37-47, 2014.

[15] N. Slesnick, G. Erdem, S. Bartle-Haring, and G. S. Brigham, "Intervention with substance-abusing runaway adolescents and their families: results of a randomized clinical trial," Journal of Consulting and Clinical Psychology, vol. 81, no. 4, pp. 600-614, 2013.

[16] B. D. Hunter, M. D. Godley, and S. H. Godley, "Feasibility of implementing the adolescent community reinforcement approach in school settings for adolescents with substance use disorders," Advances in School Mental Health Promotion, vol. 7, no. 2, pp. 105-122, 2014.

[17] S. H. Godley, B. D. Hunter, S. Fernández-Artamendi, J. E. Smith, R. J. Meyers, and M. D. Godley, "A comparison of treatment outcomes for adolescent community reinforcement approach participants with and without co-occurring problems," Journal of Substance Abuse Treatment, vol. 46, no. 4, pp. 463-471, 2014.

[18] T. F. Piehler and T. J. Dishion, "Dyadic coregulation and deviant talk in adolescent friendships: interaction patterns associated with problematic substance use in early adulthood," Developmental Psychology, vol. 50, no. 4, pp. 1160-1169, 2014.

[19] Observatorio Español de la Droga y Toxicomanías, Informe 2013. Alcohol, Tabaco y Drogas Ilegales en España. Ministerio de Sanidad, Política Social e Igualdad, Plan Nacional Sobre Drogas, Madrid, Spain, 2013.

[20] Observatorio Europeo de la Droga y las Toxicomanías, Informe anual del Observatorio Europeo de las Drogas y Toxicomanías, El problema de las drogodependencia en Europa, Oficina de publicaciones de la Unión Europea, Luxembourg City, Luxembourg, 2013.

[21] D. E. Papalia, S. W. Olds, and R. D. Feldman, Desarrollo Humano, McGraw-Hill, Bogotá, Colombia, 11th edition, 2010.

[22] M. Krank, S. H. Stewart, R. O’Connor, P. B. Woicik, A.-M. Wall, and P. J. Conrod, "Structural, concurrent, and predictive validity of the Substance Use Risk Profile Scale in early adolescence," Addictive Behaviors, vol. 36, no. 1-2, pp. 37-46, 2011.

[23] X. Guo and N. Slesnick, "The role of child gender, problem behaviors, and the family environment on maternal depressive symptoms: findings from mothers of substance abusing runaway adolescents," Journal of Community Psychology, vol. 39, no. 7, pp. 786-803, 2011.

[24] K. Klostermann and T. J. O’Farrell, “Treating substance abuse: partner and family approaches," Social Work in Public Health, vol. 28, no. 3-4, pp. 234-247, 2013.

[25] R. J. Meyers and B. L. Wolfe, Get your loved one sober: Alternatives to Nagging. Pleading and Threatening, Hazelden Press, Center City, Minn, USA, 2004.

[26] R. A. Chambers, J. R. Taylor, and M. N. Potenza, "Developmental neurocircuitry of motivation in adolescence: a critical period of addiction vulnerability," The American Journal of Psychiatry, vol. 160, no. 6, pp. 1041-1052, 2003.

[27] S. C. DeBry and S. T. Tiffany, “Tobacco-induced neurotoxicity of adolescent cognitive development (TINACD): a proposed model for the development of impulsivity in nicotine dependence," Nicotine and Tobacco Research, vol. 10, no. 1, pp. 11-25, 2008.

[28] K. M. King and L. Chassin, "A prospective study of the effects of age of initiation of alcohol and drug use on young adult substance dependence," Journal of Studies on Alcohol and Drugs, vol. 68, no. 2, pp. 256-265, 2007.

[29] R. A. Zucker, M. M. Wong, D. B. Clark et al., "Predicting risky drinking outcomes longitudinally: what kind of advance notice can we get?" Alcoholism: Clinical and Experimental Research, vol. 30 , no. 2, pp. 243-252, 2006.

[30] SAMHSA, "Results from the 2011 National Household Survey on Drug Use and Health: National Findings," (NSDUH Series H-44, HHS Publication No. (SMA) 12-4713 Rockville, Md, USA, Substance Abuse and Mental Health Services Administration from: http://www.samhsa.gov/data/NSDUH/ 2k11Results/NSDUHresults2011.pdf.

[31] A. Copello, L. Templeton, J. Orford, and R. Velleman, “The 5-step method: principles and practice," Drugs: Education, Prevention and Policy, vol. 17, supplement 1, pp. 86-99, 2010.

[32] A. B. Irvine, A. Biglan, K. Smolkowski, C. W. Metzler, and D. V. Ary, "The effectiveness of a parenting skills program for parents of middle school students in small communities," Journal of Consulting and Clinical Psychology, vol. 67, no. 6, pp. 811-825, 1999.

[33] J. W. Toumbourou, A. Blyth, J. Bamberg, and D. Forer, "Early impact of the BEST intervention for parents stressed by adolescent substance abuse," Journal of Community \& Applied Social Psychology, vol. 11, no. 4, pp. 291-304, 2001.

[34] J. W. Toumbourou and J. H. Bamberg, "Family recovery from youth substance use related problems: a pilot study of the BEST plus program," Substance Use \& Misuse, vol. 43, no. 12-13, pp. 1829-2023, 2008.

[35] J. E. Smith and R. J. Meyers, Motivating Substance Abusers to Enter Treatment Working with Family Members, Guilford Press, New York, NY, USA, 2004.

[36] R. J. Meyers, J. E. Smith, and D. N. Lash, "The community reinforcement approach," Recent Developments in Alcoholism, vol. 16, pp. 183-195, 2003.

[37] H. B. Waldron, S. Kern-Jones, C. W. Turner, T. R. Peterson, and T. J. Ozechowski, "Engaging resistant adolescents in drug abuse treatment," Journal of Substance Abuse Treatment, vol. 32, no. 2, pp. 133-142, 2007.

[38] T. J. O'Farrell and K. Clements, "Review of outcome research on marital and family therapy in treatment for alcoholism," Journal of Marital and Family Therapy, vol. 38, no. 1, pp. 122-144, 2012.

[39] R. J. Meyers, H. G. Roozen, and J. E. Smith, "The community reinforcement approach: an update of the evidence," Alcohol Research and Health, vol. 33, no. 4, pp. 380-388, 2010.

[40] C. L. Rowe, "Family therapy for drug abuse: review and updates 2003-2010," Journal of Marital and Family Therapy, vol. 38, no. 1, pp. 59-81, 2012.

[41] J. Foote and J. K. Manuel, "Adapting the CRAFT approach for use in group therapy," Journal of Behavior Analysis in Health, Sports, Fitness and Medicine, vol. 2, no. 1, pp. 109-120, 2009.

[42] G. S. Brigham, N. Slesnick, T. M. Winhusen, D. F. Lewis, X. Guo, and E. Somoza, "A randomized pilot clinical trial to evaluate the efficacy of Community Reinforcement and Family Training for Treatment Retention (CRAFT-T) for improving outcomes for patients completing opioid detoxification," Drug and Alcohol Dependence, vol. 138, no. 1, pp. 240-243, 2014.

[43] M. Ato, "Tipología de los diseños cuasiexperimentales" in Métodos de Investigación en Psicología, M. T. Anguera, J. Arnau, M. Ato, R. Martínez-Arias, J. Pascual y, and G. Vallejo, Eds., pp. 245-270, Síntesis, Madrid, Spain, 1995. 
[44] D. P. Rovira, E. E. Odriozola, and M. B. Mas, "Evaluación de La eficacia de los tratamientos psicológicos: una propuesta metodológica," Revista de Psicología General y Aplicada, vol. 46, no. 2, pp. 187-198, 1993.

[45] M. T. Cortés-Tomás and F. Pascual-Pastor, Incumplimiento de Propósitos en Drogodependencias, Radom House Mondadori, Barcelona, Spain, 2005.

[46] M. Rosenberg, La Autoimagen del Adolescente y la Sociedad, Paidós, Buenos Aires, Argentina, 1965.

[47] E. Echeburúa, Evaluación y Tratamiento de la Fobia Social, Martínez Roca, Barcelona, Spain, 1995.

[48] A. J. Vázquez Morejón, R. J. Garcia-Boveda, and R. V.-M. Jimenez, "Escala de autoestima de Rosenberg: fiabilidad y validez en población clínica española," Apuntes de Psicología, vol. 22, no. 2, pp. 247-255, 2004.

[49] A. T. Beck, R. A. Steer, and M. G. Carbin, "Psychometric properties of the Beck Depression Inventory: twenty-five years of evaluation," Clinical Psychology Review, vol. 8, no. 1, pp. 77100, 1988.

[50] J. Sanz, M. P. García-Vera, R. Espinosa, M. Fortún, and C. Vázquez, "Adaptación española del Inventario para la Depresión de Beck-II (BDI-II): 3. Propiedades psicométricas en pacientes con trastornos psicológicos," Clínica y Salud, vol. 16, no. 2, pp. 121-142, 2005.

[51] C. D. Spielberger, R. L. Gorsuch, and R. Lushene, Manual del Cuestionario de Ansiedad Estado/Rasgo (STAI), TEA, Madrid, Spain, 1982.

[52] J. J. Miguel-Tobal, M. I. Casado, A. Cano-Vindel, and C. D. Spielberger, nventario de expresión de ira estado-rasgo (STAXI2), TEA, Madrid, Spain, 2001.

[53] C. D. Spielberger, State-Trait Anger Expression InventorySTAXI-2, TEA, Madrid, Spain, 1991.

[54] T. Hothorn, K. Hornik, M. A. van de Wiel, and A. Zeileis, "Implementing a class of permutation tests: the coin package," Journal of Statistical Software, vol. 28, no. 8, pp. 1-23, 2008. 


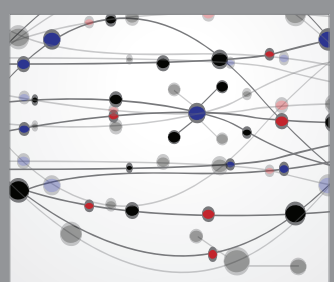

The Scientific World Journal
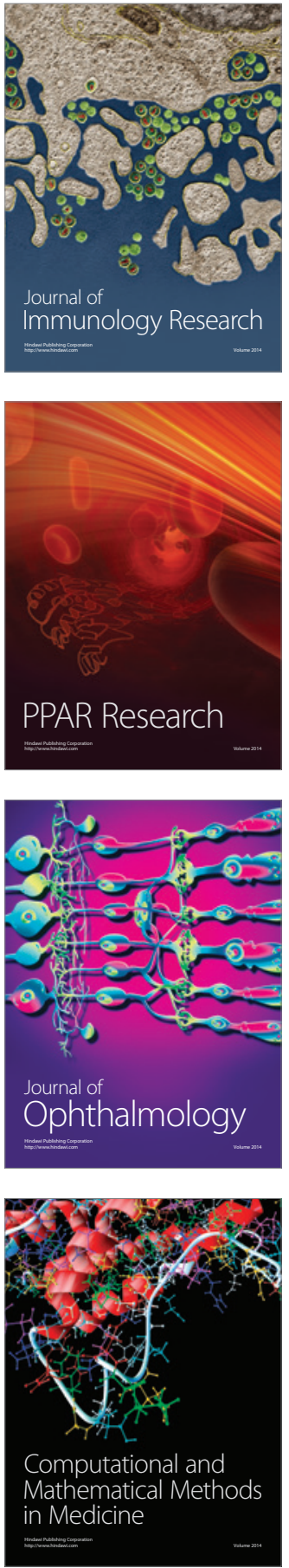

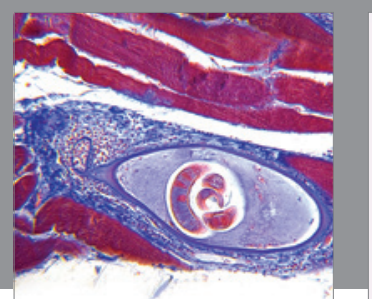

Gastroenterology Research and Practice

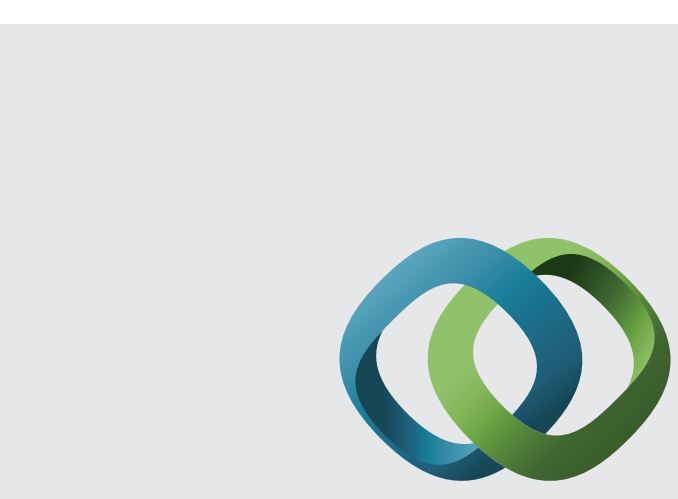

\section{Hindawi}

Submit your manuscripts at

http://www.hindawi.com
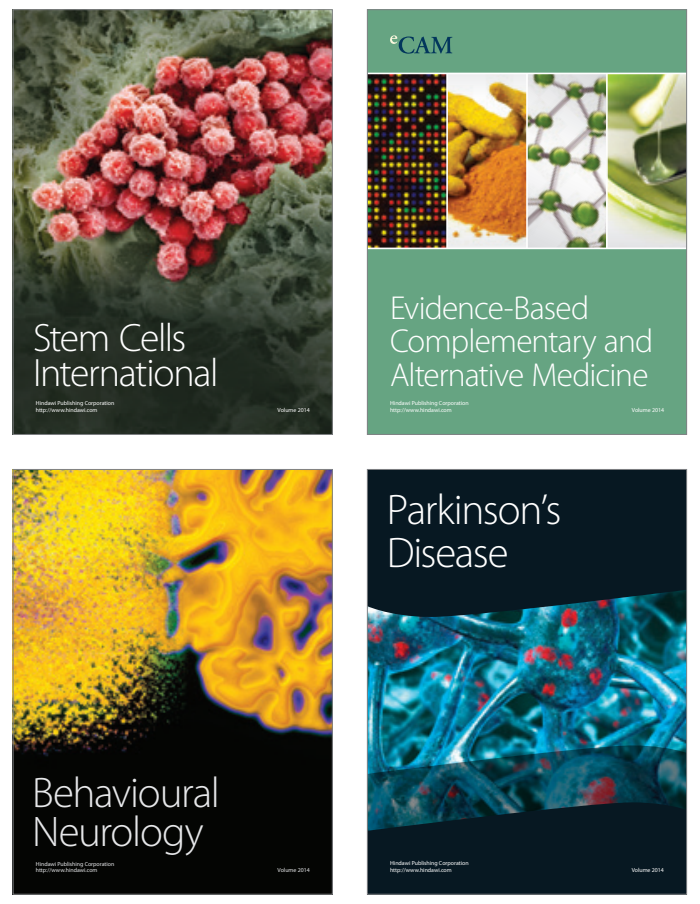
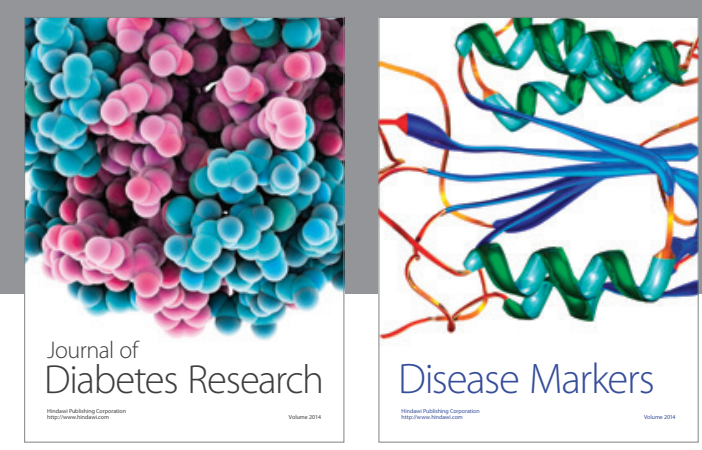

Disease Markers
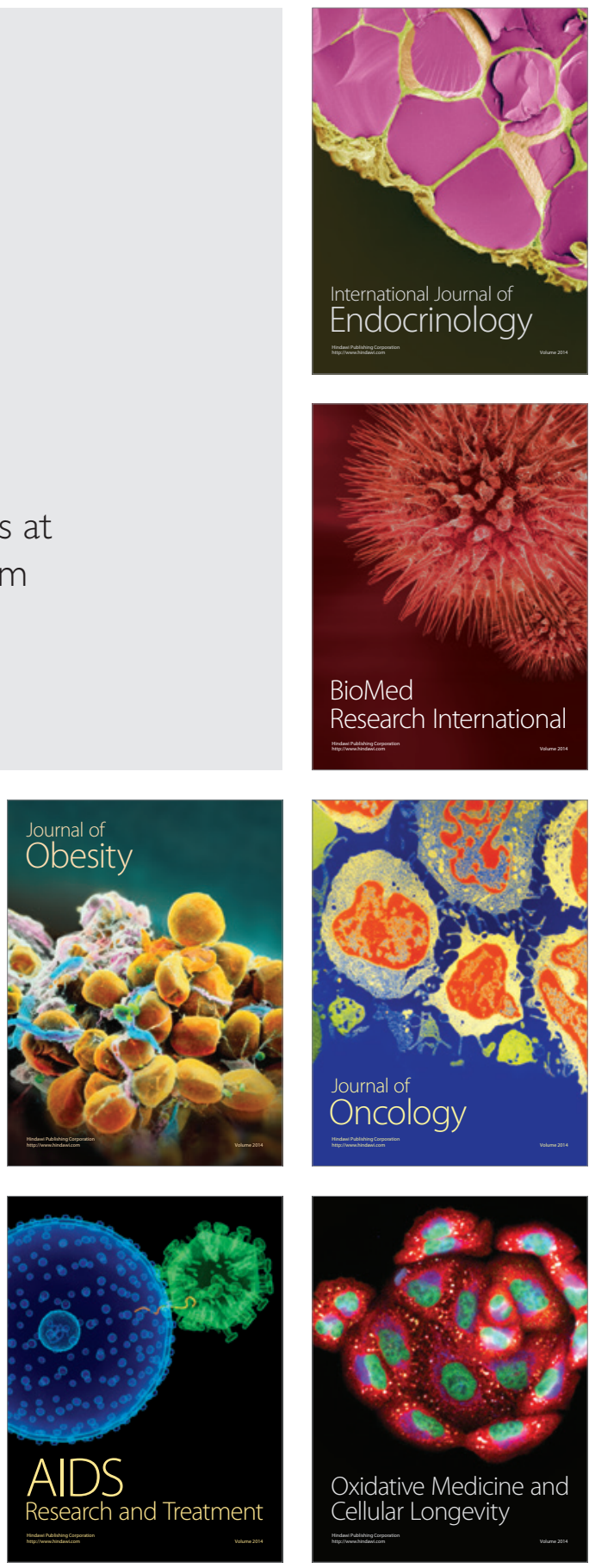